\title{
Economic Burden Evaluation of Cutaneous Leishmaniasis in Iran
}

\author{
Mojtaba Salimi ${ }^{1}$, Abedin Saghafipour (iD ${ }^{2,}{ }^{,}$, Hadi Hamidi Parsa ${ }^{3}$, Majid Khosravi ${ }^{3}$ and Mohammad \\ Reza Shirzadi ${ }^{4}$ \\ ${ }^{1}$ Research Center for Environmental Determinants of Health, Kermanshah University of Medical Sciences, Kermanshah, Iran \\ ${ }^{2}$ Department of Public Health, Faculty of Health, Qom University of Medical Sciences, Qom, Iran \\ ${ }^{3}$ Qom University of Medical sciences, Qom, Iran \\ ${ }^{4}$ Communicable Diseases Management Center, Ministry of Health and Medical Education, Tehran, Iran \\ "Corresponding author: Department of Public Health, Faculty of Health, Qom University of Medical Sciences, Qom, Iran. Tel: +98-2537842228, Fax: +98-2537833361, Email: \\ abed.saghafi@gmail.com
}

Received 2018 August 01; Revised 2018 November 24; Accepted 2018 December 01.

\begin{abstract}
Background: Cutaneous leishmaniasis as a prevalent sandfly borne disease in many tropical and subtropical countries has adverse economic consequences for patients and health care systems.

Objectives: The aim of present study was evaluation of the economic burden of cutaneous leishmaniasis on families and consequently the health care systems in all of 31 provinces of Iran for year 2017.

Methods: This cross-sectional study was carried out based on available data from 14125 cutaneous leishmaniasis cases in all endemic foci of Iran in 2017. The direct and indirect costs paid by patients and government health care systems were extracted through accounting documents via patients and health staff in the office of zoonotic diseases control, CDC, Iranian Ministry of Health. The data was recorded in researcher-made forms. Activity based costing $(\mathrm{ABC})$ is used to evaluate economic burden of health care services in Iran to patients with of CL. Two financial software suites namely Azarakhsh and Roozamad have been employed in addition to Excel V. 2010.

Results: The incidence of cutaneous leishmaniasis in Iran was 17.82 per 100,000 people (14125/79,262,000). Economic burden of the disease was estimated at 291,046,430,125 Rials $(\$ 5,820,928)$. The average direct, indirect (overhead) and governmental costs paid for each case with CL was 10,631,250 Rials (\$ 212.5), 9,653,807 Rials (\$ 193) and 20,285,057 Rials (\$ 405.5) respectively. The out of pocket for each patient was around 320 thousand Rials (\$7). Total costs (governmental + out of pocket) during this period was estimated at 20,605,057 Rials (\$ 412.5) expenditure per capita.

Conclusions: Direct and indirect costs associated with diagnosis and treatment of CL in Iran that was provided by governmental health care systems and out-of-pockets are considerably high. It can have a great economic impact on families and consequently the health care systems. It seems adopting suitable preventive methods will be more affordable for people who live at risk of the disease.
\end{abstract}

Keywords: Cutaneous Leishmaniasis, Economic Burden, Incidence, Iran

\section{Background}

Leishmaniasis as a common vector-borne disease in tropical and subtropical regions, caused by over 30 species of Leishmania parasite. It leads to a wide range of clinical signs from skin lesions to visceral infections which may lead to death (1). The disease is clinically classified into three forms: visceral, cutaneous, and mucocutaneous (2-4). Cutaneous Leishmaniasis (CL) is the most common form of the disease-causing skin lesions leaving life-long scars with delayed diagnosis and treatment (5). It is estimated that between 600,000 to 1 million new cases occur worldwide annually. In 2015, over two-thirds of new CL cases occurred in 6 countries: Afghanistan, Algeria, Brazil,
Colombia, Iran and the Syrian Arab Republic (6). According to the Center for Disease Control and Prevention, Iranian Ministry of Health and Medical Education reports, the annual incidence of CL in Iran is about 30,000 people (7). The costly diagnosis and treatment of CL combined with concomitant infection of the disease and HIV/AIDS, leading to a weakened treatment response and more severe forms of illness, has increased the importance of the disease in recent years (8). The usual microscopic method is considered as the most reliable method for the diagnosis of CL. various methods with higher sensitivity, such as modified microcrystalline, molecular and biochemical methods are also used (9). Currently, antimony metal compounds are used to treat leishmaniasis: glucantime (meglumine an- 
timoniate) and sodium stibogluconate. In recent years, cryotherapy has also been used (10-12). Economic costs of disease including all direct and indirect costs are calculated in order to determinate the burden of diseases. Direct costs are paid for treatment and indirect (overhead) costs are related to days absent from work or school due to illness (13). Previous studies show that direct and indirect costs associated with diagnosis and treatment of diseases can have a significant impact on families and thus disease control. Therefore, providing available free treatment and diagnosis facilities can affect disease control (14, 15). In other words, detailed information about economic burden of disease can help the health care decision-makers to estimate the health problem dimension, economic benefits of preventing the disease, and thus allocating funds to control the disease. The common clinical forms of CL in Iran are ZCL and ACL (16). In most of central, southern and north east areas of Iran such as Qom, Isfahan, Kerman, Khorasan provinces one or two forms of CL have been reported $(16,17)$. Commonly, integrated control methods including educating people at risk of disease in endemic areas about personal protection will be effective in disease prevention and control (18). In addition, control of sandflies and reservoir rodents are also essential parts of the disease control strategy (19). Moreover, treatment of patients under the Ministry of Health protocol imposes high costs on people and governmental health systems (20).

\section{Objectives}

This study is conducted to estimate the economic burden of cutaneous leishmaniosis on families and consequently the health care systems in Iran, for year 2017.

\section{Methods}

\subsection{Data Collection}

In this cross-sectional study, the study population included all CL patients (14125 cases) from all private and governmental medical offices and private clinics that were referred to the provincial health centers in all 31 provinces for year 2017. All human cases were referred to the laboratory after visits by the doctors and definitive diagnosis was confirmed based on detection of Leishman bodies in the smears taken from the lesion. The patients' diagnosis and treatment data of CL cases as non-urgent report from provincial health centers of all provinces were reported to office of zoonotic diseases control in CDC of Ministry of Health. The scholars followed Helsinki's ethical principles in all steps; so that patients' information remained confidential using codes for every case, without mentioning personal information such as the name, etc. and all documents were returned to the Iranian Ministry of Health archive after extracting the necessary data. Costs are received from accounting office and computer databases of the Iranian Ministry of Health were received. After holding consulting meetings with technical deputy, experts of office of zoonotic disease control and the pharmacy affairs, the needed data for calculating direct and indirect costs (overhead), government costs (direct + indirect costs) and out of pocket was recorded on the relevant forms. For instance, paying salaries to health-care providers and medical materials and devices consumed are as direct costs. In addition, building depreciation and physical spaces costs, administrative, health and treatment facilities costs and urban amenities costs were considered as indirect costs. The out of pocket costs were included the average cost of traveling, the hospitalization costs for patient and his/her fellows and their feeding costs. In addition to this, medical costs such as medical materials and devices consumed costs and non-medical costs (paying salaries to healthcare providers, building depreciation and physical spaces costs, administrative, health and treatment facilities costs and urban amenities costs) were separated. We used the statistics center's data to determine the standard rates and services. Financial documents including the documents in the accounting office of ministry of health include documents on personnel costs, supplies, pharmaceuticals and consumed and capital, medical and health care. It should be noted that these documents are available by month, title and description in the financial and accounting archives of the ministry. The documents were returned to the accounting office of the Ministry of Health archive after recording them. Patients treated with the same method were classified dividing into two categories according to the type of treatment and guidelines of the Ministry of Health: (1) systemic treatment with glucantime injection and (2) co-administration of local treatment with injectable glucantime. Local treatment was prescribed until complete recovery or up to 12 weeks maximum. Then, direct, indirect (overhead) costs and out of pocket by patients associated with the treatment services for CL patients in counties and provincial health centers were aggregated.

\subsection{Ethical Considerations}

This study was approved by the Ethics Committee of Qom University of Medical Sciences (IR.MUQ.REC.1396.23).

\subsection{Inclusion and Exclusion Criteria}

The patients with incomplete epidemiological data registration forms in previous years were excluded from 
the study. The entry criteria for the study were: residence of patients in one of the provinces that where endemic foci of disease, having a confirmed general physician certificate of confirmed disease detection, along with patients who had completed epidemiological data registration forms.

\subsection{Statistical Analysis}

Ultimately per capita cost of providing therapeutic services to patients was calculated separately.

As well as direct costs of diagnosis and treatment were include personal expenses by patients (doctor's visits, injections), personnel costs, provision of glucantime (the first-line treatment of CL in the country), materials supplying and equipment (various sizes syringes and needles, insulin syringe, surgical blade and bunch, cotton, alcohol, Giemsa stain, microscopic slide, laboratory materials, office and stationery), urban facilities costs (water, electricity, telephone). In addition, overhead costs including maintenance costs (cooler, buildings maintenance cost and equipment etc.), transportation and depreciation costs were evaluated. After collecting and determining quality the data was entered and analyzed by computer.

In this study, for calculating the economic burden of the disease, two financial and accounting software namely Azarakhsh; the software for paying salary to health staffs in Health Center of Qom province (available at: contact@roozamad.ir) and Roozamad; as an accrual accounting system and to extract operating costs for goods or services (available at: Jobs@Azarakhsh.ws) have been applied in addition to Excel software V. 2010.

Also, activity based costing ( $A B C)$ is used to evaluate economic burden of health care services in Iran to patients with of CL. Considering the benefits of ABC-based costing method such as identifying and calculating costs, possibility to prepare and present a financial and budget plan for an economic unit, the possibility of accurate control of current operations and effective planning for the future, the possibility of an accurate assessment of financialeconomic performance, this method has been selected as the appropriate costing method for this research. Activity based costing is based on the assumption that activities within each organization consume resources and products and services are the result of activities. This method first identifies all organizational activities and is recorded as cost issues, and all organizational costs are allocated to these topics. In the second stage, the basis for the defined indicators, the costs absorbed by the products or services provided, are shared (21). For converting costs into a common currency base, each dollar was considered equal to 50 thousand Rials in time of study in Iran.

\section{Results}

Totally, of 79,926,270 populations who lived in foci of CL disease in Iran; 14,125 cases (17.82 per 100,000 people) were referred to the healthcare systems of all 31 provinces in 2017 and their diseases were confirmed. Seven thousand six hundred fifty-three cases (54.18\%) were males. The mean age of the CL patients was $24 \pm 32$ years old. The economic burden of all CL patients was evaluated as 291,046,430,125 Rials $(\$ 5,820,928)$ over a study period in the country. The average direct, indirect (overhead) and governmental costs paid for each case with CL was 10,631,250 Rials; ( $\$$ 212.5), 9,653,807 Rials; (\$ 193) and 20,285,057 Rials; (\$ 405.5) respectively. The out-of pocket payments for each patient was around 320 thousand Rials; (\$ 7). Total costs (governmental + out of pocket) during this period was estimated at 20,605,057 Rials (\$ 412.5) expenditure per capita (Table 1).

As shown in Table 1, direct and overhead costs are very close to each other, as $(\$ 3,003,328) 51.60 \%$ of the costs are paid directly and remaining (\$2,727,200) $46.85 \%$ costs belong to overhead payments for the disease treatment. Table 2 shows the cost of CL elements of governmental costs associated with cutaneous leishmaniasis cases in Iran, 2017. Five major cost categories were included: paying salaries to health-care providers, medical materials and devices consumed (glucantime purchasing, consumed material costs including syringe, cotton, alcohol, etc.), building depreciation and physical spaces costs, administrative, health and treatment facilities costs and urban amenities costs.

\section{Discussion}

In the present study, the economic costs of CL patients were estimated at nearly 6 million $\$$ over a study period (2017) in Iran. In this study, we found out that more than $15 \%$ of governmental costs was consumed for paying salaries to health-care providers. Other previous studies indicate that the largest portion in a disease imposed costs is related to involved personnel costs. For example, in a same study in three hospitals in Ghana, the cost of personnel was estimated at $40 \%-60 \%$ of total costs (22). In another study in the intensive care unit of a hospital in Germany, staff costs consisted the largest part of costs with $42 \%$ of total costs (23). In general, personnel costs are said to be about $60 \%$ of total direct costs (24). So, although the cost of human resources in this study is the highest proportion of the total, it has not exceeded acceptable levels.

The expenditure per capita (governmental + out of pocket costs) for CL treatment in different countries is between \$ 300 and \$ 1200 (25). In the present study, the av- 


\begin{tabular}{|c|c|c|c|}
\hline \multirow{2}{*}{ Major Costs Groups } & \multicolumn{3}{|c|}{ Health Care Costs } \\
\hline & Total Costs of Cases $(14125 / 79262000)$ Rials $(\$)^{a}$ & $\%$ Out of Total Costs & Expenditure Per Capita Rials (\$) \\
\hline Direct costs & $150,166,406,250(3,003,328)$ & 51.60 & $10,631,250(212.5)$ \\
\hline Indirect costs (overhead) & $136,360,023,875(2,727,200)$ & 46.85 & $9,653,807(193)$ \\
\hline Governmental (direct + indirect) costs & $286,526,430,125(5,730,528)$ & 98.45 & $20,285,057(405.5)$ \\
\hline Out of pocket & $4,520,000,000(90,400)$ & 1.55 & $320,000(7)$ \\
\hline Total costs (governmental + out of pocket) & $291,046,430,125(5,820,928)$ & 100 & $20,605,057(412.5)$ \\
\hline \multicolumn{4}{|l|}{${ }^{\mathrm{a}}$ One dollar =50,000 Rials. } \\
\hline Major Cost Groups & \multicolumn{2}{|c|}{ Expenditure Per Capita Rials (\$) } & \% Out of Governmental Costs \\
\hline Paying salaries to health-care providers & $43,661,716,875(873,234.33)$ & $3,091,095(61.82)$ & 15.24 \\
\hline Medical materials and devices consumed & $106,510,692,500(2,130,213.85)$ & $7,540,580(150.81)$ & 37.17 \\
\hline Building depreciation and physical spaces costs & $39,730,828,250(794,616.56)$ & $2,812,802(56.25)$ & 13.87 \\
\hline Administrative, health and treatment facilities costs & $16,035,632,250(320,712.65)$ & $1,135,266(22.70)$ & 5.60 \\
\hline Urban amenities costs & $80,587,560,250(1,611,751.21)$ & $5,705,314(114.10)$ & 28.12 \\
\hline Total & $286,526,430,125(5,730,528.6)$ & $20,285,057(405.5)$ & 100 \\
\hline
\end{tabular}

erage direct, indirect (overhead) and governmental costs paid for each case with CL was 10,631,250 Rials; (\$ 212.5), 9,653,807 Rials; ( $\$ 193$ ) and 20,285,057 Rials; (\$ 405.5) respectively. The out of pocket payments for each patient was around 320 thousand Rials; (\$ 7). In other words, the expenditure per capita for CL in Iran at this period (2017) was estimated at \$ 412.5. So, we can conclude that expenditure per capita for CL in Iran resembled other countries. In addition, this finding matches the findings of the Aflatoonian et al. study about the cost of CL in Bam, Iran ( \$ 70) (8), but has a huge disparity with countries like Guatemala (about \$ 280) and Peru (about \$ 300) $(26,27)$ which might be because of establishment of a care system for CL in Bam after the earthquake as well as presence of the specialists from Kerman University of Medical Sciences. The results of study in Bam is similar to the findings of present study that obtained in all provinces of Iran, since most patients refer to governmental health centers and pay less due to using public facilities. In contrast of the results of present study, Iraji and Tavakoli in the study on CL treatment costs in the Isfahan province carried out in 1999 were indicated that the highest portion of costs after miscellaneous expenses (46.30\%), in both urban and rural areas, was related to medications (16.66\%), followed by physician visits (13.37\%), injections and wound dressings (12.86\%), transportation (4.48\%) and finally laboratory costs (6.32\%). Also according to Iraji and Tavakoli findings, per capita cost of treatment for every patient in rural area was about 454527 Rials and in urban regions 208307 Rials. Physician cast expended per capita was 53830 Rials in urban area and 31736 Rials in rural districts, which 34536 Rials and 20657 Rials was paid by patient, respectively, and the rest by insurance companies, mainly through free or low cost government facilities (28). As observed by Aflatoonian et al., 2570 million Rials was spent for $5320 \mathrm{CL}$ patients in the years after the earthquake in Bam, during the years 2005 - 2006, with 483676 Rials per capita cost wherein $90 \%$ were spent directly and the remaing 10\% included indirect costs (8).

In this present study, medical materials and devices consumed (glucantime purchasing, consumed material costs including syringe, cotton, alcohol, etc.), were more than $37 \%$ of all governmental costs. In the same study carried out in psychiatric hospital services at a public health facility in Nigeria, $4.4 \%$ of the total cost was spent on materials and supplies, respectively (29). It seems that the cost of consumed equipment to treat CL patients is lower than findings in other areas; however, it is necessary to be reduced by standardizing consumption and improving the staff skill in proper use of the devices as much as possible. One hundred million Rials, near 10\%, belongs to direct costs of receiving urban amenities (water, electricity, telephone, and transportation). In a research conducted in the Dialysis Department of Shahid Sadoughi Hospital in Yazd, this cost was estimated to be $0.64 \%$ of a total respectively (30). Therefore, the cost of urban amenities for treating CL patients seems appropriate compared with other stud- 
ies. It seems that mentioning the low cost of urban amenities compared to other costs could be due to subsidies paid by the government to public health centers. It should be noted that the findings of this study show a minor part of the problems caused by $\mathrm{CL}$ (economic costs only) and the psychosocial and social aspects of the disease could not be forgotten, since the present study only explores the economic and financial costs of the disease for the affected and public sector due to complexity of such problems. In addition, the estimated sample does not consist all cases of CL in Iran that is one of disadvantages and limitations of the studies based on recorded data, but the results seem to be partly indicating total costs spent on health care services provided to patients with CL in Iran.

\subsection{Conclusions}

According to the results of this study, the direct and indirect costs associated with the diagnosis and treatment of CL in Iran, which are provided by public healthcare systems and out of pocket paid by patients, are relatively high. The health services providers and people to treat this disease suffer greatly. Therefore, it is recommended to take basic disease preventive strategies, such as people awareness alongside performing public preventive measures in high risk areas of CL disease in order to prevent CL. It seems these preventive interventions will reduce prevalence of disease and its related economic burden respectively.

\section{Acknowledgments}

The authors would like to express their gratitude for collaboration of all health staff working in health centers of all provinces and the personnel working in office of zoonotic disease control of Iranian Ministry of Health because of their cooperation in the study implementation.

\section{Footnotes}

Authors' Contribution: Mojtaba Salimi and Abedin Saghafipour co-designed the study, Abedin Saghafipour and Hadi Hamidi Parsa were the project designers of the research and wrote the manuscript. Abedin Saghafipour, Majid Khosravi and Mohammad Reza Shirzadi participated in collecting the data and Hadi Hamidi Parsa analyzed the results. All authors read, modified, and approved the final version of the manuscript.

Conflict of Interests: There are no financial conflicts of interest to disclose.

Ethical Approval: This study was approved by the Ethics Committee of Qom University of Medical Sciences (IR.MUQ.REC.1396.23).
Funding/Support: This study was financially supported by Qom University of Medical Sciences (IR.MUQ.REC.1396.23).

\section{References}

1. Hotez PJ, Savioli L, Fenwick A. Neglected tropical diseases of the Middle East and North Africa: Review of their prevalence, distribution, and opportunities for control. PLoS Negl Trop Dis. 2012;6(2). e1475. doi: 10.1371/journal.pntd.0001475. [PubMed: 22389729]. [PubMed Central: PMC3289601].

2. Akhoundi M, Kuhls K, Cannet A, Votypka J, Marty P, Delaunay P, et al. A historical overview of the classification, evolution, and dispersion of leishmania parasites and sandflies. PLoS Negl Trop Dis. 2016;10(3). e0004349. doi: 10.1371/journal.pntd.0004349. [PubMed: 26937644]. [PubMed Central: PMC4777430].

3. David CV, Craft N. Cutaneous and mucocutaneous leishmaniasis. Dermatol Ther. 2009;22(6):491-502. doi: 10.1111/j.1529-8019.2009.01272.x. [PubMed: 19889134].

4. Handler MZ, Patel PA, Kapila R, Al-Qubati Y, Schwartz RA. Cutaneous and mucocutaneous leishmaniasis: Clinical perspectives. J Am Acad Dermatol. 2015;73(6):897-908. quiz 909-10. doi: 10.1016/j.jaad.2014.08.051. [PubMed: 26568335].

5. Salam N, Al-Shaqha WM, Azzi A. Leishmaniasis in the middle East: Incidence and epidemiology. PLoS Negl Trop Dis. 2014;8(10). e3208. doi: 10.1371/journal.pntd.0003208. [PubMed: 25275483]. [PubMed Central: PMC4183486].

6. Alvar J, Velez ID, Bern C, Herrero M, Desjeux P, Cano J, et al. Leishmaniasis worldwide and global estimates of its incidence. PLoS One. 2012;7(5). e35671. doi: 10.1371/journal.pone.0035671. [PubMed: 22693548]. [PubMed Central: PMC3365071].

7. Norouzinezhad F, Ghaffari F, Norouzinejad A, Kaveh F, Gouya MM. Cutaneous leishmaniasis in Iran: Results from an epidemiological study in urban and rural provinces. Asian Pac J Trop Biomed. 2016;6(7):614-9. doi: 10.1016/j.apjtb.2016.05.005.

8. Aflatoonian MR, Sharifi I, Fekri AR. [Evaluation of the costeffectiveness of cutaneous leishmaniasis treatment after the earthquake in Bam]. J Kerman Univ Med Sci. 2009;16(4):365-73. Persian.

9. Pazoki-Ghohe H, Haghparast-Kenari B, Fakhar M. [Current and novel laboratory diagnostic methods and identification of causative agents for cutaneous leishmaniasis]. J Mazandaran Univ Med Sci. 2016;25(132):350-66. Persian.

10. Haldar AK, Sen P, Roy S. Use of antimony in the treatment of leishmaniasis: Current status and future directions. Mol Biol Int. 2011;2011:571242. doi: 10.4061/2011/571242. [PubMed: 22091408]. [PubMed Central: PMC3196053].

11. Brito NC, Rabello A, Cota GF. Efficacy of pentavalent antimoniate intralesional infiltration therapy for cutaneous leishmaniasis: A systematic review. PLoS One. 2017;12(9). e0184777. doi: 10.1371/journal.pone.0184777. [PubMed: 28926630]. [PubMed Central: PMC5604971].

12. Shirzadi M, Gouya MM. National guideline for Leishmaniasis surveillance in Iran. Tehran, Iran; 2012.

13. Jo C. Cost-of-illness studies: Concepts, scopes, and methods. Clin Mol Hepatol. 2014;20(4):327-37. doi: 10.3350/cmh.2014.20.4.327. [PubMed: 25548737]. [PubMed Central: PMC4278062].

14. Seuring T, Archangelidi O, Suhrcke M. The economic costs of type 2 diabetes: A global systematic review. Pharmacoeconomics. 2015;33(8):81131. doi: 10.1007/s40273-015-0268-9. [PubMed: 25787932]. [PubMed Central: PMC4519633]. 
15. Foster N, Vassall A, Cleary S, Cunnama L, Churchyard G, Sinanovic E. The economic burden of TB diagnosis and treatment in South Africa. Soc Sci Med. 2015;130:42-50. doi: 10.1016/j.socscimed.2015.01.046. [PubMed: 25681713].

16. Shirzadi MR, Esfahania SB, Mohebalia M, Ershadia MR, Gharachorlo F, Razavia MR, et al. Epidemiological status of leishmaniasis in the Islamic Republic of Iran, 1983-2012. East Mediterr Health J. 2015;21(10):736-42. [PubMed: 26750164].

17. Saghafipour A, Vatandoost H, Zahraei-Ramazani AR, Yaghoobi-Ershadi MR, Jooshin MK, Rassi Y, et al. Epidemiological study on cutaneous leishmaniasis in an endemic area, of Qom province, central Iran. J Arthropod Borne Dis. 2017;11(3):403-13. [PubMed: 29322057]. [PubMed Central: PMC5758636].

18. Saghafipour A, Nejati J, Mozaffari E, Rezaei F, Gharlipour Z, Mirheydari M. The effectiveness of education based on BASNEF model on promoting preventive behavior of cutaneous leishmaniasis among students. Int J Pediatr. 2017;5(6):5125-36. doi:10.22038/ijp.2017.22373.1875.

19. Saghafipour A, Vatandoost H, Zahraei-Ramazani AR, Yaghoobi-Ershadi MR, Rassi Y, Karami Jooshin M, et al. Control of zoonotic cutaneous leishmaniasis vector, Phlebotomus papatasi, using attractive toxic sugar baits (ATSB). PLoS One. 2017;12(4). e0173558. doi: 10.1371/journal.pone.0173558. [PubMed: 28426679]. [PubMed Central: PMC5398489].

20. Saghafipour A, Mozaffari E, Rezaei F. The evaluation of intralesional glucantime and cryotherapy plus intralesional glucantime therapeutic efficacy on zoonotic cutaneous leishmaniasis: A randomized clinical trial. Int J Pediatr. 2017;5(12):6689-97. doi: 10.22038/ijp.2017.24545.2069.

21. Rajabi A. The role of activity based costing ( $A B C)$ system in governmental hospital services in Iran. Iran Red Cres Med J. 2008;10(2):89-94.

22. Aboagye AQ, Degboe AN, Obuobi AA. Estimating the cost of healthcare delivery in three hospitals in Southern Ghana. Ghana
Med J. 2010;44(3):83-92. [PubMed: 21327011]. [PubMed Central: PMC2996840].

23. Goeree R, Gafni A, Hannah M, Myhr T, Blackhouse G. Hospital selection for unit cost estimates in multicentre economic evaluations. Does the choice of hospitals make a difference? Pharmacoeconomics. 1999;15(6):561-72. doi: 10.2165/00019053-199915060-00004. [PubMed: 10538329].

24. Shepard DS, Hodgkin D, Yvann AE. Paydar A, translator. Analysis of hospital costs: A manual for managers. Tehran: Sogand Publication; 2001.

25. Reithinger R, Coleman PG. Treating cutaneous leishmaniasis patients in Kabul, Afghanistan: Cost-effectiveness of an operational program in a complex emergency setting. BMC Infect Dis. 2007;7:3. doi: 10.1186/1471-2334-7-3. [PubMed: 17263879]. [PubMed Central: PMC1790896].

26. Arana BA, Mendoza CE, Rizzo NR, Kroeger A. Randomized, controlled, double-blind trial of topical treatment of cutaneous leishmaniasis with paromomycin plus methylbenzethonium chloride ointment in Guatemala. Am JTrop Med Hyg. 2001;65(5):466-70. [PubMed: 11716099].

27. Guthmann JP, Arlt D, Garcia LM, Rosales M, de Jesus Sanchez J, Alvarez E, et al. Control of mucocutaneous leishmaniasis, a neglected disease: Results of a control programme in Satipo Province, Peru. Trop Med Int Health. 2005;10(9):856-62. doi:10.1111/j.1365-3156.2005.01460.x. [PubMed: 16135192].

28. Iraji F, Tavakoli R. Expense of treatment of cutaneous Leishmaniasis in Isfahan province in 1999. Iran J Dermatol. 1999;4(16):3-7.

29. Ezenduka C, Ichoku H, Ochonma O. Estimating the costs of psychiatric hospital services at a public health facility in Nigeria. J Ment Health Policy Econ. 2012;15(3):139-48. [PubMed: 23001282].

30. Mohammadi Y, Baghestani E, Bahrami MA, Entezarian Ardekani S, Ahmadi Tehrani GH. [Calculating the cost price of dialysis in Shahid Sadoughi Hospital using activity based costing: Yazd, 2011]. J Health Account. 2012;1(1):73-84. Persian. 